\title{
La unidad en Hegel
}

\author{
LEONARDO POLO \\ Universidad de Navarra
}

\section{LA UNIDAD CIRCULAR DEL SISTEMA HEGELIANO}

Planteamos a Hegel un problema de unidad: ¿hay una única filosofía hegeliana? Es decir, ¿la génesis de su planteamiento es completa, es unitaria?.

Porque Hegel se ocupó de muchos asuntos: de lógica, interpretándola en su pensamiento como metafísica. También se ocupó, y abundantemente, de la historia. Y en la Fenomenología del espíritu trata de una enorme cantidad de cosas: como el arte, la religión, la cultura. Y Hegel se ocupó también del estado, de la organización de la sociedad: prácticamente es el fundador de la sociología. Y también intentó, como es natural, hacer una filosofía del mundo, una filosofía de la naturaleza.

Y entonces planteamos: $¿$ es posible decir que todo ese material constituye una unidad desde el punto de vista del sistema, es decir, desde el punto de vista de su génesis, de la derivación de unas cosas respecto de las otras? ¿Hegel ha constituido un sistema general completo y unitario?

Eso parece; especialmente si nos fijamos en la Enciclopedia; sobre todo en la última edición, la de 1830, que amplía mucho la primera, la del 17. Algo que a Hegel le ocurría siempre: que empezaba queriendo escribir algo corto, y luego se inflaba. Y con la Enciclopedia le pasó eso: que al final se hinchó enormemente; y la edición póstuma, en que además están las anotaciones de los discípulos, ya es un libro de unas 800 páginas aproximadamente. Pues, si uno se atiene al plan de la Enciclopedia, podría decirse que más o menos Hegel piensa este conjunto de temas. Hay una filosofía de la naturaleza. Hay una antropología: una filosofía del hombre, en tanto que el hombre no es simplemente un ser puramente físico o un animal. Después hay una filosofía del

1 Este texto está tomado de las clases impartidas por Leonardo Polo entre el 20 de marzo y el 2 de abril de 1982, dentro de un curso de Introducción a Hegel aún inédito; ello explica el tono coloquial, que confiamos disculpe el lector. 
espíritu absoluto. Y también está la lógica. Como a su vez al final de la lógica, y por un procedimiento curioso que es la alienación, sale la naturaleza; entonces resulta que el conjunto viene a ser como un círculo. La filosofía sistemática de Hegel es unitaria de modo circular.

De una parte, el espíritu absoluto tiene tres miembros: son el arte, la religión y la filosofía; por filosofía se entiende lógica o metafísica. Pero resulta que la filosofía es también historia de la filosofía, porque Hegel quiere hacer corresponder la historia de la filosofía con la estructura de la lógica. Y la lógica tiene a su vez tres miembros: la filosofía del ser, la de la esencia y la del concepto. Pues digo que esta división tiene un cierto carácter histórico. Es decir, según Hegel, las primeras categorías, las primeras nociones lógico-metafísicas de la historia de la filosofía habría que colocarlas en el ámbito del ser. La filosofía de la esencia sería ulterior, fundamentalmente la filosofía que aparece en Espinoza y en Leibniz. Y luego viene la filosofía del concepto, que es lo último, es su propia filosofía, su añadidura a la historia de la filosofía.

El concepto culmina en la idea absoluta; la idea absoluta se aliena, y al alienarse tenemos la filosofía de la naturaleza. La naturaleza también se divide en tres miembros: el estado físico, que a veces también se llama mecánico, el estado químico y el estado orgánico de la vida.

Al final de lo orgánico aparece el hombre, y aquí entonces tendríamos la antropología de Hegel. Pero, para hacer la cosa trimembre, habría que decir algo así como esto: por un lado tenemos la naturaleza y por otro el espíritu absoluto. Resulta que en la filosofía del espíritu aparecen el estado, la moralidad y otros asuntos así: esto es el espíritu. Pero la antropología tiene que ser también espíritu; luego será espíritu subjetivo, una primera parte; y entonces la otra será el espíritu objetivo. Y finalmente el espíritu absoluto.

Así, el espíritu subjetivo tiene tres miembros: la antropología, la fenomenología del espíritu - algo un poco raro meter aquí la Fenomenología, pero no cabía en otro sitio y la metió aquí - y la psicología. La filosofía del espíritu subjetivo es una filosofía del hombre; la Fenomenología del espíritu es más bien una filosofía de las facultades; por lo menos, los primeros tres o cuatro capítulos. Todo esto sería el estudio del hombre como sujeto o también el estudio de la individualidad humana. La filosofía del espíritu objetivo tendría tres partes: el derecho, la moral y la eticidad; todo esto es su filosofía de la sociedad civil y de la familia, que están metidas en la filosofía del derecho. También su filosofía del estado, su filosofía de la economía, de la técnica; porque Hegel tiene también una filosofía de la técnica, una teoría del maquinismo. Y luego, por encima de todo eso, el espíritu absoluto: el arte, la religión y la filosofía.

Una filosofía historificada, que se puede a su vez distribuir sistemáticamente en ser y esencia, hasta Hegel, y concepto en Hegel. Volvemos a la idea, alienación de la idea, y al círculo. 
Hegel habla del círculo, y del círculo de círculos, porque a su vez todas las partes son circulares. De manera que si el todo es un círculo, también cada parte es un círculo.

La idea del carácter circular del sistema, en donde radicaría su unidad, no es un invento hegeliano; puesto que la noción de círculo como lo más perfecto, como aquello en que todo se ordena y unifica, es una idea perfectamente griega. Está en Parménides, en Platón y en Aristóteles.

Considerada la estructura general de la Enciclopedia en su unidad, ya se ve ahí que no es la filosofía de Jena, no es la Fenomenología del espíritu. Su primera parte ha sido metida dentro de la filosofía del espíritu subjetivo. Algunas otras cosas, como una filosofía de la moralidad, ahora han sido metidas en el espíritu objetivo. Y las alusiones, que también son bastante importantes, al arte, la religión y la filosofía se han metido en el espíritu absoluto.

Y además tenemos otro problema: ¿dónde está la historia? Habría que considerar que es todo; o sea que la filosofía del espíritu y la historiología coincidirían. Sin embargo, en la Fenomenología del espíritu la filosofía de la historia está al final de la obra, con lo cual es evidente que en la Enciclopedia la estructura ha sido modificada. El que se atenga a la Enciclopedia como el resumen sintético sistemático de la filosofía de Hegel no puede aceptar como definitiva la estructura de la Fenomenología del espíritu.

Este enfoque de la unidad del pensamiento hegeliano, basado en la Enciclopedia, es hasta cierto punto forzado. Según él todo es demasiado unitario, porque en el fondo - como dice Hegel, y es una observación que también está en Aristóteles - en el círculo el comienzo y el fin están en el mismo sitio; por eso es por lo que es perfecto. Es decir, cualquiera de los puntos de la circunferencia, si consideramos como un proceso a la circunferencia misma, es comienzo y fin. De manera que el fin de la lógica es el comienzo de la filosofía de la naturaleza, y el comienzo de la lógica el fin de la naturaleza, y viceversa. Esa idea que está presente en la mente de Hegel desde muy temprano, aunque se plasme de una manera muy temática en la Enciclopedia, de esa propiedad curiosísima que tiene la circunferencia de que todos los puntos son comienzo y término. Esa idea en cierto modo es una idea forzada, es decir, con eso Hegel no resuelve el problema de la sistematicidad de su pensamiento; pienso que es un poco artificial esta ordenación.

Tal vez se entienda mejor la cuestión procediendo de otra manera; es decir, si distinguimos los tres miembros: la filosofía del espíritu, la lógica y la filosofía de la naturaleza. Entonces realmente la continuidad estricta del círculo se nos rompe, pues tendríamos tres arcos, a cada uno de los cuales les corresponde una temática distinta. El tratamiento de la idea en sí sería la lógica. Fuera de sí, la naturaleza. Y la filosofía de la historia, el espíritu, sería el en sí y para sí. Dios en sí, Dios fuera de sí, Dios en sí y para sí. 
Esto de poner el sí antecedido de una proposición, este juego de proposiciones, es un recurso al que Hegel apela, aunque tampoco es del todo correcto, o es un poco artificial; pero introduce cierta precisión respecto del carácter que podríamos llamar tranquilo y completamente sin problemas que la noción de circularidad parece llevar consigo. Porque ahora tenemos que los distintos sectores del círculo ya no son estrictamente equivalentes; ya que el en sí, el fuera de sí y el para sí, tienen características cualitativas diferentes, cosa que si se trata de una circunferencia no podríamos decir, puesto que la circunferencia es homogénea en todas sus partes. O sea que al distinguir prepositivamente el estatuto de la idea introducimos algo de precisión respecto del puro círculo, que es algo vago para establecer la unidad del sistema hegeliano.

\section{HEGEL Y EL NEOPLATONISMO}

Para aclarar un poco más esto, podríamos hacer una comparación con el neoplatonismo, sobre todo con Proclo, al que Hegel considera uno de los máximos filósofos: el que cierra la filosofía clásica, para él tan querida, y tan privilegiada, porque para Hegel es la gran filosofía.

Las proposiciones hegelianas (en sí, fuera de sí, para sí) se parecen bastante a la idea de Proclo de que hay una salida y una vuelta. Una procesión desde la hipóstasis suprema y un retorno ulterior: sale de sí y vuelve a sí. El esquema neoplatónico también es circular, pero es circular de otra manera; es más bien una alternativa circular: así o así; la circularidad está aquí en el salir $y$ en el volver.

Sin embargo, esta comparación con los neoplatónicos tampoco nos acaba de dar la clave del problema de la unidad sistemática de la filosofía de Hegel, por lo menos el neoplatonismo de Proclo. Porque, para los neoplatónicos, la salida es la emanación; en ella se producen las hipóstasis, la realidad distinta de la primera; esto es la procesión (proodós). Y con el retorno (epistrofé) se intenta la reunificación de lo que ha procedido. Sin embargo este esquema no sirve exactamente para Hegel. Porque lo que sería equivalente a la salida, lo que él llama fuera de sí, no es más que la naturaleza; pero la naturaleza no permite la constitución del todo inteligible. Donde está lo importante es realmente en la vuelta desde ella. De manera que, siguiendo a Hegel, más bien habría que decir que donde se constituyen las hipóstasis, donde se constituye estrictamente la realidad, es en el retorno, no en la salida.

Quizás, si no a Proclo, a Plotino se le podría interpretar en este sentido. En su historia de la filosofía Hegel propone una interpretación de las Enéadas de Plotino en que la salida se recupera en cada momento. Es decir, en Plotino no se trataría de una salida entera y de una vuelta entera, sino que habría una salida con vuelta, y otra con otra vuelta; y al final para evitar un problema de proceso al infinito hay que conceder que no hay estrictamente vuelta completa. 
Así serían el nous y el alma; la vuelta no se da enteramente, porque la vuelta es un proceso al infinito. Primero estaría el uno, que es de donde emana una potencialidad, la cual en vuelta es el nous; otra potencialidad, que en vuelta es el alma; y después está la materia, que realmente no vuelve del todo, o cuya vuelta es un problema. ¿Esta manera de ver de Plotino es exactamente la de Hegel?

Pues tampoco es exactamente lo mismo, porque en cualquier caso, el problema está en la filosofía de la naturaleza; que tal como la entiende Hegel no es asimilable a ninguno de estos planteamientos, porque es lo primero que procede de la idea. Para los neoplatónicos lo primero que procede es el nous y luego el alma; la naturaleza, el mundo material, no es lo primero sino lo último. Y, por otra parte, el retorno no se hace desde la naturaleza: la naturaleza no tiene retorno. En Hegel la filosofía de la naturaleza está haciendo de fase intermedia, pero al mismo tiempo de fase alienada (a diferencia de la fase alienada de Plotino que sería la última fase); fase intermedia desde la cual se puede producir la vuelta que es el "en sí y para sî", pero se produce después del extremo alejamiento que es el fuera de sí.

Con lo cual tampoco la comparación con los neoplatónicos nos proporciona una mayor precisión, sino más bien una diferencia. Nos damos cuenta de que Hegel no es estrictamente un neoplatónico, de que tanto su manera de entender el fuera de sí, es decir, lo que procede de la idea del absoluto, como el modo con el que entiende la vuelta desde la salida, son distintos de lo que piensan Proclo o Plotino.

Yo creo que la cuestión fundamental sería, en último término, porque es lo original, entender qué es la filosofía de la naturaleza de Hegel; o cómo la filosofía de la naturaleza es una continuación circular, o en qué sentido lo es, de la metafísica o de la lógica. Decir que la tesis es la lógica, la antítesis la naturaleza y la síntesis el espíritu, no soluciona nada, no es exacto. La unidad del pensamiento hegeliano sigue siendo un problema.

Tenemos que dar un paso adelante y tratar de entender el punto clave de Hegel; tendríamos que intentar ver a Hegel desde sus intenciones peculiares. En este momento, al ver que la idea del círculo no es tan cómoda, o que no se puede aplicar a Hegel tan fácilmente como podría parecer o como a veces los intérpretes la dan a entender; al plantear esa diferencia con el neoplatonismo sobre el modo como se entiende el fuera de sí y la vuelta, yo creo que aquí habría que ver cuál es el móvil central del pensamiento de Hegel, qué es lo que Hegel en último término toma como ideal, qué es lo que pretende, a dónde quiere ir; y porqué queriendo ir allí, y al ocuparse de toda la temática posible, le resulta ese conjunto de temas que han salido en la Enciclopedia; puesto que, en las grandes conexiones entre ellos, por ejemplo en la conexión entre la lógica y la naturaleza, está el problematismo enorme que tiene la unidad del 
pensamiento hegeliano.

\section{LA PRETENSIÓN DE UNIDAD ABSOLUTA}

Vamos a ver si lo entendemos, y si les digo qué es lo peculiar de Hegel: qué es lo que a Hegel le interesa por encima de todo, o qué es lo que a Hegel le mueve como una pretensión muy personal, que es lo más original suyo, y con relación a la cual todos sus estudios y exposiciones, su uso de la dialéctica, todo está dirigido a ver si vale para resolver lo que Hegel pretende. Esto seguramente, si lo consideramos con un poco de atención, nos introducirá en lo que hay de más problemático, de pretensión irrealizable, en Hegel.

El asunto en cierto modo es muy bello; y desde otro punto de vista sumamente desagradable: porque en lo que Hegel pretende hay, por decirlo así, un pecado intelectual; motivo por el que la herencia de Hegel es positivo-negativa, o explica que Hegel haya tenido tan mala influencia, tan destructora. Yo creo que es una intención que se impone a Hegel, y desde la cual Hegel lo interpreta todo; está constantemente siendo esgrimida, y cuando Hegel poco a poco la va reconociendo es cuando también poco a poco va pudiendo incorporar nuevos asuntos a su planteamiento. Vamos a ver si se lo explico.

Tal vez podríamos empezar por el impacto que le produjo a Hegel la lectura de la Crítica de la razón práctica de Kant.

Piensen ustedes en un señor cuyas primeras lecturas son Rousseau y sus amados griegos, un historiador que está entusiasmado por el ideal de armonía que capta en la existencia griega clásica, de la Hélade. Y, de pronto, lee una obra sobre ética en la cual la tesis central, tal como puede ser vista por un joven que tiene aquellas ilusiones, ideales y entusiasmos, es que si se quiere llegar a una situación perfecta, a una situación de culminación, la más alta manera de ser ético implica el sacrificio de todo el resto del hombre; es decir, se trata de una ética de imperativo legal, que exige para ser enteramente pura que ningún motivo humano, ningún sentimiento, ningún móvil, ninguna dimensión de las que hace que la existencia humana sea humana de los pies a la cabeza, el hombre entero podríamos decir, pueda ser tenida en cuenta.

La ética de Kant es una ética absolutamente desequilibrada, antropológicamente desequilibrada. Para que el hombre sea estrictamente ético tiene que cumplir o atenerse al imperativo categórico, y no puede atenerse más que a ese deber, porque en cuanto se tiene en cuenta lo que en el hombre no es la voluntad pura sublimada en la noción de deber, eso se muestra como una impureza radical. Es decir, que si yo doy limosna por compasión, por un sentimiento de solidaridad, o si doy limosna incluso porque quiero tener una justificación ante mí mismo..., todo eso destroza el carácter ético del dar limosna. Porque si doy limosna es porque hay que dar limosna y nada más, por respeto al deber. Es el carácter estrictamente formal de la ética kantiana, que no admite de ninguna 
manera contenido alguno. El formalismo ético de Kant está seguramente en la base del enfado de Hegel contra lo meramente formal, que se aprecia en su lógica.

Esto a Hegel le produjo un sentimiento de terrible desazón, porque contrastaba enormemente con el ideal armónico griego. La ética griega no es la kantiana; por lo menos la ética clásica, aunque quizás no la estoica, que se parecería más a la ética kantiana. Hegel tenía la idea de que todo el hombre puede ser promovido a perfección, porque esto es lo que sacaba de los griegos; es decir, que si queremos ver una figura humana plena, un ser humano perfecto, tenemos que verlo, y esto es otra de las características del pensamiento de Hegel, como una especie de elevación de todo su ser hasta la plenitud; pero tal que en esa elevación de todo su ser hasta la plenitud no se quede nada fuera, sin justificación.

Es decir, la perfección humana, por decirlo así, es una perfección que empieza en los pies y acaba en la cabeza. Pero en la que al subir desde los pies a la cabeza, no se prescinde de aquéllos, ni de nada intermedio. Es como un perfeccionamiento desde la base, pero un perfeccionamiento en que no se elimina nada, en que no se desprecia nada, en que el hombre es enteramente perfecto: en sus sentimientos, en sus deseos, en sus pasiones, en su tragedia humana, es decir, en la integridad de su personalidad psicológica y también en la integridad de su personalidad voluntaria y en la integridad de su personalidad a secas. Claro la palabra persona en Grecia no tiene mucho sentido, pero, en fin: en la integridad del individuo que es llevado a lo universal, de una conducta que está por encima de lo particular; pero haciendo ascender todos los dinamismos de su ser hasta allí.

El contraste entre la ética kantiana y la ética griega para Hegel no podía ser mayor. Quizás ese contraste no es tan áspero, porque a mí me parece que el absolutismo ético es un error total; y aquí lo que pasa es que están luchando dos tipos de absolutismo ético. Están luchando una interpretación griega de la vida como éticamente perfecta, o el ideal de vida griego como un ideal de hombre perfecto, en el que coincide exactamente la perfección ética con la perfección qua talis. Mientras que en Kant ocurre todo lo contrario, en Kant lo que ocurre es que la cosa más alta que hay es la voluntad ética. "Hay dos cosas que despiertan mi admiración -decía Kant- el cielo estrellado por la noche sobre mí y la ley moral impresa en mi voluntad". Admirable, pero tan admirable que a eso hay que sacrificarlo todo, mientras que no asume nada; es perfecto, pero en solitario, absolutamente en solitario. La perfección ética de Kant es un ápice, pero es un ápice que no asume nada; sino un ápice que para ser realizado exige destacarse de todo, descalificando a todo lo demás.

Es decir, que si el hombre quiere la perfección ética tiene que declarar que todo lo que no es perfección ética se distingue de la perfección ética, y por lo 
tanto es estrictamente imperfecto. A los ojos de Hegel, a los ojos de un clasicista como era Hegel en su juventud, Kant es un maniqueo. Kant sostiene en la Crítica de la razón práctica que en el hombre no hay nada bueno más que una buena voluntad, y que todo lo demás es malo; de modo que si se mezcla de alguna manera con la conducta ética, que entonces ni siquiera puede ser una conducta, no puede ser más que puro respeto al imperativo absoluto, entonces lo des-absolutiza y lo desgracia. Las pasiones... jasquerosas!; lo que dice Kant por ejemplo del instinto sexual es una cosa horrible. Pero igual todo lo demás, por ejemplo la compasión; si usted se mueve por compasión no se mueve por deber y se ha cargado usted la eticidad.

Lo que Hegel observa en Kant es lo que toda su vida fue su problema: lo que él llama el monstruo; no la bestia negra, que es la economía, sino el monstruo. El monstruo para Hegel es la escisión: el desgarramiento, la falta de armonía, el viejo ideal armónico griego, que él llama conciliación. La ausencia de conciliación; el que las cosas sean enemigas, de tal manera que lo mejor sea enemigo de lo bueno, hasta tal punto que lo simplemente bueno no puede ser bueno; hasta tal punto llega eso, que la unidad del hombre se desgarra. Si el hombre quiere dar limosna, al mismo tiempo tiene que hacer un arrasamiento de todo lo que hay de material humano que acompaña al acto ético de dar limosna, porque si no ese acto humano no es ético, como dice Kant. Esto le produjo a Hegel su famosa crisis hipocondríaca: el darse cuenta de que ese bello ideal de armonía en que el hombre es enteramente un ser asumido por lo perfecto, era derribado por Kant.

Lo que Hegel intenta por encima de todo es la conciliación. Ha descubierto como una cosa que le ha helado el corazón - diríamos poéticamente, pero asî fue-, que ese ideal de armonía, según el cual todo el hombre es perfecto, es cuestionado por Kant; $y$ entonces hay que superar el desgarro interior del hombre. Cuando se llega a la cumbre de la perfección todo el resto del hombre es elevado, en lo que Hegel llama la aufhebung, al grado supremo, y participa de ese grado supremo. Esto Kant lo niega en redondo, y esto despierta en Hegel hasta tal punto un recelo de alarma, por decirlo así, que empieza a encontrar escisiones por todas partes. Empieza a notar, y lo notó durante toda su vida, que el ideal de armonía, de conciliación, está constantemente siendo desmentido; que las cosas están separadas cada una por su lado, y que se pegan palos los unos a los otros.

Y que es dudosa la idea de una perfección, que diríamos, de tipo vegetal; porque ese modelo de perfección, de unidad, que buscaba es vegetal. Eso es su filosofía de la esencia; después en su Ciencia de la Lógica, ya pasa de la vida al concepto. Pero Hegel entiende inicialmente la armonía griega con la idea de lo que le pasa a una planta: que empieza siendo una semilla, pero crece y crece en perfección de una manera homogénea, hasta llegar a la flor; de tal manera 
que la flor es circular cuando da el fruto y vuelve a empezar. Un maravilloso y espléndido despliegue de la perfección de una planta, en que no hay escisión ninguna, sino que toda la planta es llevada ella misma a su propia perfección desde su propio origen; de manera que todo el ser de la planta consiste en ir de menos a más, pero entera, sin escisión alguna. Ese ideal organicista y vegetal de la perfección, que es el que él tiene en su juventud, que es su manera de entender a los griegos - quizás incorrecta pero es la suya-, todo eso ha venido un leñador llamado Kant con un hacha y se lo ha ido liquidando. Frente a la bella elasticidad de la perfección de la planta, frente a eso bello-ético que es el ideal griego, tenemos otras maneras de proceder que son mecánicas, a base de palos y de golpes, una gresca. El horror que tiene Hegel a la técnica, al mecanicismo, se debe también a esto.

Se puede pensar que el punto de arranque, el momento en que se condensa para Hegel una tarea filosófica, es la experiencia de este contraste; experiencia que no es una pura constatación de una diferencia entre los griegos y Kant, sino que es una experiencia en la que él se siente comprometido, una experiencia vívida. Lo cual implica, claro está, que Hegel se pone del lado de los griegos, interpretándolos como un caso ideal de conciliación, un ideal que creo que se podría llamar vegetal.

\section{EL TODO Y LAS PARTES}

Es el ideal de que todo está en todo, esa vieja frase de Anaxágoras que ha sido siempre uno de los grandes acicates de la filosofía occidental. En Platón concretamente, la influencia de esa frase de Anaxágoras, en la base de la doctrina de las homeomerías, es - yo creo- al menos tan importante como el fermento socrático. El aislamiento, la separación, el estar cada cosa por su lado, o cada mochuelo en su olivo, el que cada palo aguante su vela..., esta serie de expresiones en las que se produce una especie como de retracción que se expresa en una autosuficiencia, en el solipsismo; eso es justamente lo más contrario y lo menos afín al espíritu de Hegel. El espíritu de Hegel con lo que comunica es con que todo tiene que ver con todo, o que todo está en todo; el todo es todo y es todo totalmente. Él tenía una gran admiración por el axioma aristotélico según el cual "el todo es anterior a las partes", anterior con prioridad absoluta, no con prioridad temporal como es natural; y que a su vez las partes se entienden en el todo; y también que para entender el todo hay que entender las partes. Una íntima compenetración que exige varias cosas: exige que lo inferior comunique con lo superior, por una parte; es decir, que el ascender no se deje nada atrás, que la ascensión no sea hecha de una manera orgullosa. Exige a su vez que nada se retire a una fingida autosuficiencia, que es desmentida íntimamente por la parcialidad: si no hay nada más que una unidad celosamente recabada, entonces esa unidad no es tal unidad. Parte y todo. Las partes sólo 
pueden existir en el todo; y por otra parte, claro está, si el todo se separa de las partes o se aísla de ellas como un todo sin partes, pues resulta manifiestamente un todo a su vez separado, y por lo tanto un todo particular.

De manera que si hablamos de dialéctica, así en una primera aproximación, sería una dialéctica de las partes y el todo; o una dialéctica de lo finito y lo infinito, o de la identidad y la diferencia. No hay Dios sin mundo - dice-; y habría que decir también: no hay mundo sin Dios. Ésta es, por así decirlo, la justificación de Hegel a sus propios ojos, el modo de hacer propia una tarea pensante, porque ese ideal no está realizado de una manera total. Es decir, que si axiomáticamente el todo es anterior a las partes, no hay partes sin todo, y la autonomía de las partes es falsa; por otra parte, también es cierto que las partes a veces se toman como todo, y no solamente a veces, sino en muchas ocasiones de la vida ordinaria, y como lo más normal.

Una filosofía del absoluto para Hegel es una filosofía de la totalidad. Se puede decir que esto es un monismo, pero más bien es un panteísmo, porque es un monismo que no es del monon único, puesto que el único, que es la solución de Parménides, es insuficiente. Recuerden ustedes que Anaxagoras viene después de Parménides, aunque a veces se lo incluye en los manuales bajo el epígrafe de los físicos pluralistas. Pero aquí tenemos otra vez replanteado ese problema, tan profundo por otra parte, de lo uno y lo múltiple. Lo múltiple no puede ser meramente múltiple, tiene que ser uno; y al revés, lo uno no puede ser simplemente uno, tiene que ser necesariamente también múltiple.

Desde este ángulo se puede ver lo que Hegel esté intentando hacer. Es evidente que la lectura de la Crítica de la razón práctica tuvo que ser una experiencia muy dolorosa para Hegel: la manifestación clara de que estaba ante un caso de escisión; y por otra parte paradigmático, puesto que se trata de una obra muy importante. En su tiempo aún más, pues en ella se inspira Fichte, y Fichte era entonces un filósofo de escándalo, de actualidad. En cambio, Kant no es un filósofo de la totalidad, eso es manifiesto. Aún en la Crítica del juicio, Kant parece pensar de otra manera, porque la Crítica del juicio es una filosofía casi organicista, en la que Kant afronta fundamentalmente el tema del organismo; y el organismo es un modelo de totalidad. En cierto modo se puede decir que el pensamiento de Hegel es organicista: la mano es la mano del cuerpo, un cuerpo sin manos no es el cuerpo, etc. Seguramente este ideal de totalidad completa al final se tiene que resolver sintéticamente a la fuerza; no hay otra solución, si las partes no pueden prescindir del todo y el todo no puede prescindir de las partes: lo que sale es un embutido a la fuerza.

La tremenda escisión de Kant no es más que un caso de escisión, un caso de desgarramiento. Que además se ve con cierto patetismo; en el que se evidencia que en Hegel no está ausente la pasión. Hegel era un filósofo frío, un filósofo serio; pero es un hombre también trabado por una profunda emoción. 
Esto del todo y las partes es emocionante para él. Hay una profunda decisión al respecto: Hegel no quiere de ninguna manera un mundo hecho de átomos. El atomismo le pone malo, porque cada átomo es individual, particular, aislado. El atomismo es una mala solución dentro de una física parmenídea. Frente al monismo parmenídeo se intenta resolver el problema de la pluralidad, pero se resuelve repartiendo la unidad en los múltiples, y eso es la noción de átomo. El átomo es absolutamente uno consigo mismo, eso es lo que significa átomo; ya no se reduce a ser parte de uno, sino uno consigo; pero justamente por eso hay una pluralidad de átomos, los átomos pueden ser infinitos incluso. Un mundo hecho de átomos es lo más horroroso para Hegel.

Esto enlaza con la experiencia romántica. Hay distintas opiniones sobre si Hegel es un romántico o no. Porque en Hegel hay una fuerte crítica, un fuerte rechazo del romanticismo, en cuanto que el romanticismo para Hegel es un intento prematuro de encontrar la totalidad de una manera inmediata. Pero el inmediatismo no es una totalidad en la que las partes sean lo concreto de la totalidad. Ven ustedes que se está dibujando, aunque en este momento Hegel aún no pensaba así, todavía no tenía clara la solución, el concepto, la noción de universal concreto, que va a ser la solución definitiva. Cuando Hegel encuentra que la única manera de llevar a cabo la totalidad es el universal concreto, la totalidad complicada con las partes, el que todo esté en todo de manera que sea un todo total, no un todo separado y abstracto. El concepto no es abstracto de ninguna manera; lo particular es lo abstracto; lo particular es la parte no integrada en la generalidad vacía. La dialéctica del átomo y el vacío será democrítea, pero de ninguna manera puede ser hegeliana. Si es que se le puede llamar dialéctica a esto; en definitiva, más que una dialéctica, es una lógica erística la que hay detrás de Demócrito.

Hegel es un crítico de la curiosa manera como el romanticismo busca la conciliación, la totalidad. Es inmediata; pero también sumamente emotiva, estética; y también influida por una nueva comprensión del clasicismo de los griegos; pero incapaz de dar razón de todas las dimensiones, para que todo esté en todo. Si las partes son partes del todo, son partes amontonadas, simplemente desorganizadas; y entonces ¿cómo se organizan?, ¿cómo tienen que ver unas con otras?

\section{EL CONCEPTO Y LA UNIDAD LÓGICA}

El problema es la relación interna que las partes tienen dentro del todo. Si las partes no están inertemente dentro del todo, si las partes no forman parte del todo como los granos de un montón de arena, si no se trata de un puro amontonamiento de partes, si no se trata de una totalidad accidental, entonces el todo tiene que proporcionar a las partes su propia vinculación. En cuanto que las partes están vinculadas las partes tienen que estar en una relación que 
es evidentemente racional; puesto que una relación vivida, estrictamente establecida, tiene que ser una relación sabida: lo real es racional. En la fórmula del concepto como universal concreto, lo concreto es lo real, lo universal es lo racional; pero lo concreto está traspasado de racionalidad, puesto que el todo proporciona a las partes el conectivo.

Por aquí empezamos a notar que en Hegel hay un conectivo lógico, que es un conectivo interno al concepto; algo que naturalmente tiene cierta novedad. Hegel rechaza el conectivo judicativo y los conectivos demostrativos, puesto que el juicio y la demostración no constituyen un estricto todo. Una demostración tiene corolarios, consecuencias; y las consecuencias no están enteramente integradas en ella, son algo que sigue: la consecuencia sigue a las premisas en un silogismo; por eso está fuera de las premisas. El fuera es una manera de escisión.

Dicen que yo siempre funciono con la diferencia entre dentro y fuera; pero no es del todo cierto. Hegel sí que funciona con esa diferencia; diferencia importantísima para alguien que quiere realizar el lema de Anaxágoras, es decir, que quiere revivir a Platón. Porque Platón enmienda el renuncio de Anaxágoras: que lo homeomérico por excelencia sea el nous. Eso Anaxágoras no lo lleva a cabo - dice Platón - . En Anaxágoras el pensar la totalidad en términos de nous está establecido de forma programática, pero después el nous no cumple la tarea que Anaxágoras parecía asignarle. Hay en Anaxágoras lo que yo llamo un renuncio; a los ojos de Platón, y a los ojos de Aristóteles también. De manera que al final las homeomerías de Anaxágoras son excesivamente materiales. Yo suelo decir que son como esponjas recíprocas, para que una cosa no sea externa a otra. Como el nous no funciona para realizar el modelo del todo en todo, entonces Anaxágoras tiene que recurrir a la interpretación material de la homeomería. Donde hay una homeomería están todas las demás, pero ¿cómo pueden estar todas las demás si esto se piensa de una manera materialista? En la forma de una esponja: cada homeomería es una esponja relativamente a todas las demás. Que todo esté en todo materialmente significa, por ejemplo, que la incompatibilidad de lugar no tiene sentido, que todo es traspasable. Dos cosas no pueden estar en un solo lugar; la cantidad implica eso. Pues Anaxágoras tiene que pretender, esto es su pensamiento homeomérico, que sí; y creo que eso se puede pensar de esa manera: como esponjas recíprocas. Todas las homeomerías están embebidas de todas las otras. Pero entonces tendríamos un universo homeomérico sin nous. Eso no puede ser, no es la solución racional del tema del conectivo.

De todas maneras Aristóteles no piensa que la conclusión sea tan externa a las premisas como Hegel opina. Hegel realmente leyó a Aristóteles, pero hay mucha cosa de Aristóteles que no entendió. Y es evidente que no es un lector suyo lo suficientemente atento, a pesar de la gran admiración que le 
tiene; porque Aristóteles dice que la conclusión es un propio de las premisas. Es un propio no es un destacado de las premisas. Hay quien ve la conclusión como válida por sí misma, de tal manera que el camino para llegar a ella es accidental, pero eso contrasta fuertemente con lo que dice Aristóteles. Y eso ocurre justamente porque se cree que el juicio es similar a la demostración. Y entonces se subordina la estructura de la demostración a la del juicio. Hegel incluso subordina la estructura de la demostración y la del juicio a la estructura del concepto: es mucho más radical. Y al mismo tiempo mucho más primitivo en lógica que quien investigue el conectivo judicativo o intente investigar el conectivo fundamental, el conectivo deductivo que naturalmente también hay que repensar. Aristóteles no lo pensó del todo bien, puesto que al final resulta que el conectivo silogístico es un puro conectivo combinatorio. La tesis de las figuras del silogismo en Aristóteles tiene que ser profundamente revisada; eso es manifiesto y sin embargo no está siendo revisado por los lógicos actuales, porque los lógicos actuales siguen siendo combinatorios. El álgebra de Boole es una pura combinatoria.

Hegel está buscando un modelo suficiente para realizar el lema de Anaxágoras. En este sentido Anaxágoras sería un griego por excelencia según Hegel. Y en cuanto que Aristóteles y Platón se dan cuenta del renuncio de Anaxágoras y quieren llevar a cabo su programa en términos de nous, aunque de una manera distinta uno del otro, naturalmente Platón y Aristóteles son para Hegel también grandes griegos.

Estamos en la totalidad con interno conectivo, ¿qué es lo que quiere decir que todo está en todo?. Si todo está en todo, todo está conectado en el todo. ¿Cómo está estrictamente conectado en el todo? De tal manera que pertenecer al todo como parte no rompa la unidad, no sea analítico de ninguna manera, sino que supere la razón de parte. Éste es el último problema al que Hegel pretende dar solución.

Es manifiesto que este problema no tiene solución, o mejor dicho que es un problema mal planteado; porque los problemas que no tienen solución son problemas mal planteados. No existe tal conectivo conceptual. En Platón hay un conectivo conceptual, fundamentalmente, que sería la cuestión de las notas. Un concepto es una idea, y está constituido por notas; entonces el problema de la relación entre las notas, es el problema del conectivo conceptual; si es que la idea está hecha de notas. Hay otro modelo más moderno, muy inferior al de Hegel desde luego, al conectivo que Hegel es capaz de aportar para establecer su noción de universal concreto, que es la noción de estructura propia del estructuralismo. El estructuralismo es un pensar holístico, de totalidades; en el que las totalidades tienen elementos, y el problema es cómo se relacionan esos elementos. Los modelos estructuralistas son matemáticos, algo torpes, o muy imperfectos. El estructuralismo, como versión de un pensamiento holís- 
tico, anaxagórico, se deja fuera casi todo; y además precisamente porque el conectivo estructural es en el fondo demasiado analítico. Este es el problema de la analítica, por eso en Hegel esté funcionando la noción de síntesis; bien entendido que se trata de síntesis conceptual.

Y digo que esto no es resoluble ni como lo resuelve Platón, ni como Hegel ni como lo resuelve un estructuralista. El estructuralismo es una forma de hegelianismo, o si quieren de platonismo, porque es una filosofía de la causa formal, es un análisis de lo que llama Aristóteles la causa formal, es un análisis eidético. En Husserl también está: todo el problema de la conciencia constituida es otro asunto de este orden, es una estructura lógica. ¿Cómo una estructura lógica es suficientemente unitaria?, ¿cómo los miembros lo son, sin que el ser miembros los anule difundiéndolos en una totalidad confusa que rompa su propia condición de miembros, ni tampoco los permita aislarse? Ésta es la cuestión.

Les decía que es lo mismo que un vegetal. Aristóteles afirma que el vegetal no cumple bien el modelo unitario, puesto que el alma del vegetal es divisible, se pueden hacer esquejes; el alma vegetal es divisible. Esta profunda sentencia aristotélica, que los biólogos pasan por alto como casi todo lo que es profundo, responde exactamente a que Aristóteles también se está planteando el problema de si hay suficiente unidad; y en un vegetal no la hay.

Sin embargo, el problema no tiene solución en los términos de Hegel, ni tampoco en los de Platón, ni en los términos de un estructuralista. El conectivo de un saber absoluto, absolutamente integrado, perfectamente unitario, no tiene solución por una simplísima razón; y es porque eso está fuera de nuestro alcance racional. Sólo si entendemos que la razón humana es la razón divina, sólo si admitimos la identidad, o lo que es igual, el carácter absoluto de nuestra propia razón, sólo entonces podemos sostener eso. Es la idea del monofisismo radical de Hegel: que la razón humana es la razón divina, y entonces la razón humana hará lo que hace la razón divina. Pero con eso se estropea tanto la razón humana como la divina, porque a la razón humana se le encarga una tarea que ella es incapaz de cumplir, y naturalmente a la razón divina se la compromete profundamente con las insuficiencias de la razón humana.

El modo divino de resolver este problema - además Dios es el único que lo puede resolver en absoluto - es lo que se llama la simplicidad, la simplicidad de Dios. La simplicidad para nosotros es un misterio. Dios no es un embutido de la totalidad; ¡cómo va a ser Dios un todo con partes, aunque sean partes absolutamente interpenetradas!, ¡cómo se va a pensar a Dios homeoméricamente, aunque en términos de nous, o en términos de concepto!; ; eso es de locos!, eso es quedarse sin lo más grande. Hay un ateismo subrepticio en Hegel, y es decir que Dios tiene que ser así, que el absoluto tiene que ser un todo; pero un todo según el modelo de contener partes, y eso no es aplicable a Dios. Dios no se constituye; Dios no es analítico pero tampoco sintético. Síntesis y análisis son 
operaciones mentales de nuestra cuenta. Tampoco tiene sentido descalificar enteramente el análisis a favor de la síntesis; es también un error, pero menor en comparación. Pero como teólogo - y esto es una teología en el fondo, también para un griego esto es teología - , como alguien que aspira a saber en absoluto, a conocer el absoluto, Hegel es un auténtico fracaso; y es un auténtico fracaso porque Dios no es concepto. Dios no tiene ese conectivo que le da Hegel, ni el que le da Platón tampoco.

Por eso desde cierto puto de vista se puede decir que Hegel es un inmanentista, aunque a mí esa palabra no me gusta nada porque me parece que tampoco resuelve gran parte de las cuestiones. Pero si empleamos la palabra inmanentista en este sentido, tal vez: para alguien que es monofisita, y para designar a quien aspira a entender el absoluto; y entonces para entender el absoluto tiene que entender la totalidad como constituida por constituyentes parciales, de tal manera que los eleva a su propio carácter de todo, y por lo tanto los conecta estrictamente para evitar que sus constitutivos se parcialicen o se quasi absoluticen en cuanto que divididos y distinguidos. Yo eso nunca lo podré hacer, porque no se puede hacer. Yo a lo que más llegaré es a una unificación, y siempre que hay conectivo hay unificación, pero a la simplicidad, no; la simplicidad tiene que trascender esto a la fuerza. La simplicidad es el todo infinitamente intensivo, sin análisis ni síntesis; y eso para nosotros es un misterio. La esencia de Dios es un misterio. Hegel lo que quiere es que no sea tal misterio; por eso Hegel es un monofisita, y un gnóstico. Porque el gnóstico, que es la forma realmente propia de herejía, achaca una imperfección al todo; y ya puedo forjar unos modelos para que las partes no se me parcialicen, que en cuanto ponga composición en el absoluto, he desabsolutizado el absoluto. ¿Qué significa simple? Pues a la fuerza lo que trasciende a la composición. Hegel no lo quiere admitir, y en cierto modo tiene que retroceder desde un planteamiento fundamental, ni siquiera a uno judicativo, sino que tiene que ir al planteamiento conceptual; tiene que invertir la marcha progresiva de la razón humana y quedarse en su primer estadio que es el concepto.

¿Por qué? Pues por el lema de Espinoza: ordo et conexio rerum idem est ac ordo et conexio idearum; y el ordo et conexio idearum cuando es judicativo es más desligado que cuando se trata de conceptos; y cuando se trata de la demostración todavía más. El juicio y la demostración, mirándolos desde el concepto, son como dilataciones, y en esas dilataciones los integrantes tienen una cierta autonomía. ¿Cuál es la conexio en Hegel? El concreto; y ¿qué significa concreto? Mediación. La clave de la noción de concreto es el "con". Las partes son copartes: crecen juntas, viven juntas, se remiten intrínsecamente unas a otras; y es así como las partes no se particularizan en el universal que es el todo.

Si uno quiere encontrar la unidad trascendentalmente respecto del juicio, 
está apelando a una unidad que no es solamente universal, sino más amplia. El retroceso del juicio al concepto en el monofisismo de Hegel tiene esta traba: la ampliación. No ya el problema del mit-, de la Vermitlung, del concretum, cumcrescere, crecer juntos; otra vez lo vital, la vida, el crecer y medrar juntos. Eso cree Hegel que puede ser el intrínseco conectivo real del universal; pero con eso pierde que la unidad trascendental del juicio es trans-universal y transcategorial, más amplia que la de conceptos y categorías. En Hegel hay un angostamiento de la noción de todo porque el universal concreto es un angostamiento de la totalidad, ya que la universalidad no es la totalidad; es mucho más amplio un juicio que un concepto; y es mucho más amplia una demostración que un juicio. Si uno se plantea el tema de lo trascendental, se encuentra que en Hegel lo trascendental está comprimido, y lo está para que no se le unan de ninguna manera elementos ajenos a la presencia.

Pero es que en presencia no cabe todo; en nuestra presencia mental no cabe todo, y Hegel quiere que quepa todo y eso no puede ser. Hegel está jugando una mala partida a nuestro conocimiento. La lógica de Hegel es un tremendo error; y es un error como todos los errores, por defecto. Porque si es verdad que nosotros tenemos que pensar conectivamente y tenemos que pensar universalmente, tenemos que darnos cuenta a la vez de que somos capaces de establecer una noción de unificación y unos conectivos y una amplitud lógica superior a la del concepto. ¿Y si no? Empequeñecemos, reducimos nuestra propia razón. Y si encima se la endosamos a Dios, lo hemos rematado y fastidiado todo. Vean ustedes cómo grandes ilusiones, grandes tareas pensantes, están acuciadas por una necesidad psicológica; Hegel está acuciado por esa necesidad de vencer las escisiones.

\section{LA FALTA DE LÓGICA EN LA ÉPOCA}

Hegel es romántico. El romanticismo de Hegel es la crítica al inmediatismo. Lo inmediato no puede ser concreto: lo inmediato es indeterminado. Lo inmediato es ajeno a la contraposición fundamental entre inmediación y mediación. El concepto es mediación a la fuerza: un concepto inmediato es una frustración de la conceptuación misma. Estamos recordando a Anaxágoras, pensador que ha lanzado un gran lema: hay que conectar, o sabemos totalidades o no sabemos de verdad. Pero, ¿cómo sabemos nosotros totalidades? Conectando, no sabemos de otra manera. ¿Por qué? Porque no sabemos la totalidad en su simplicidad. Pero entonces a todo lo que sea separación hay que declararle la guerra, y Hegel se la declara; eso es asumir el drama romántico, porque la conciencia romántica es el desenlace de lo que Hegel llama la conciencia desgraciada; la conciencia desgraciada es justamente la autoconciencia que no se reconoce.

Pero eso no es más que la expresión del drama romántico porque el romanticismo, como situación espiritual, lo que hace es recibir brutalmente, amontonar, 
todas las divergencias dinámicas, todas las herejías (herejía significa separación) europeas. De pronto, el romanticismo se encontró con que la herencia del XVI y XVII, yo diría que desde el XIV, no es más que una dispersión: la voluntad por un lado y la razón por otro; la muerte y la vida; el dualismo cartesiano; el espíritu, la sensibilidad, la intuición intelectual, todo es un conjunto, ¿de qué? Todo es oposición; y ¿qué es la oposición? La imposibilidad de reconocimiento total, el monstruo de la escisión. Cuando Hegel, cargando la mano, dice que esto se debe a la ruptura de la bella unidad griega, apunta que el monstruo de la escisión es anterior, está en el imperio romano. Con esto, naturalmente, Hegel lo que hace es extrapolar la edad moderna.

Newton es un mundo de átomos, ¿qué tiene que ver Newton con un organismo? Nada; es la destrucción, el desgarramiento por desmembración. Consideren ustedes, por ejemplo, el tercer principio de la mecánica de Newton, el principio de acción y reacción; y verán que si no se piensa como absoluto lo particular, ese principio no se puede montar. Acción-reacción, tanto da; porque se trata de la indiferencia entre los átomos. Como todos los átomos son átomos, todos son iguales; entonces si hay un empuje por un lado tiene que haber un contraempuje por el otro, y además igual y coinstantáneo. Este es el principio de la acción-reacción. El mismo golpe que yo le doy a esto, es el golpe que al golpear recibe de eso. Una estricta compensación, casi economicista: tanto te pego, tanto me pegas. La mecánica es la ley del talión de las fuerzas, ¿por qué? Porque de antemano lo que tiene cada cuerpo es una vis insita, una fuerza que le es propia en exclusiva; y como a todos les pasa igual, en cuanto a uno se imprime una fuerza, una vis impresa, esa vis impresa se compensa exactamente con la vis insta, de manera que los dos principios de Newton terminan en el tercero. Newton es perfectamente sistemático en su definición de los principios. Pero entonces, ¿qué es esto? Es un mundo de átomos y un mundo absolutamente desgarrado, es un mundo para llorar como decía Hobbes. Hobbes se pasó la vida lamentando. ¿Qué le pasa a esto que está muerto? No hay un impulso naciente, no hay un impulso creciente, porque todo impulso se para con el contraimpulso. Vida y mecánica, una contraposición desgarradora. Entre Rousseau y Newton hay un abismo, si tiene razón Rousseau no la puede tener Newton. Y si tiene razón Newton no la puede tener Rousseau. ¿Cómo voy yo a concentrar mi vida en un instante de gozo, si la realidad en su estructura consiste en choques y reacciones?. Y entonces en esa instantaneidad en que se suman las fuerzas contrarias y dan una resultante nula, ¿dónde surge ahí la vida? Si es un instante muerto, el instante en que no cabe nada, es como un punto.

A eso Hegel llama la alienación del tiempo, una de las nociones con las que Hegel quiere hacer frente a la escisión: es la etiqueta que pone a esta experiencia profunda, de que la conciliación no se ha conseguido. En la Fenomenología del espíritu intenta exponer esto de alguna manera, pero es un primer ensayo de 
exposición, realmente precedido por otros. La escribe cuando Hegel entiende que la manera de resolver el problema del todo en todo es el concepto.

Pero antes había intentado ver si lo podía resolver de otra manera, a saber, acudiendo al amor; puesto que el amor también tiene un carácter unitivo. Pero no; el amor fracasa porque puede ser despreciado; no hunde sus raíces en la totalidad, aportándola; aunque quiera, el amor fracasa, y si no se convierte en el gran inquisidor. El inquisidor de Dostoievski está ya presente en Hegel, cuando el amor quiere forzar resultados. Cuando los otros se niegan a amar, el amor no tiene más remedio que acudir a la estaca; y cuando acude a la estaca se niega a sí mismo. El procedimiento unitivo del amor no es lo suficientemente poderoso.

Luego dice si no es el amor, será la vida, porque es muy diferente de la mecánica. Después de hacer un intento de filosofía de la vida, por fin ya se rinde Hegel, y forja la noción de concepto como arma especulativa. Quien realmente la forja es Fichte, y Hegel no podía repetir a Fichte; sin embargo, no tiene más remedio que coger el concepto; y entonces aparece el idealismo hegeliano que es la base de la Fenomenología del espíritu.

Pero no está bien desarrollada, ni siquiera en terminología hegeliana. En esencia no es más que esto: hay una primera parte en la que tenemos el modo según el cual la mediación es intrínsecamente mediación. Pero la vermitung no es la aufhebung: la mediación no es sólo la mediación entre distintos, sino que debe ser la superación de la distinción mediante la conservación elevadora; y la superación es una elevación de los distintos hasta la concepción. Los dos momentos antes del tercero, todavía no consiguen la aufhebung; por lo tanto no se median entre sí, es pura negación dialéctica; la mediación en sentido estricto, la negación especulativa, es la concreción, y para que haya concreción hace falta elevación, aufhebung. La Fenomenología del espíritu es esto. La escisión y su conciliación: cómo se arma, dónde tiene que armarse y de qué forma la autoconciencia; por eso la Fenomenología del espíritu es la teoría de las figuras de la conciencia a partir de la escisión radical que para Hegel es la oposición dialéctica.

Tendremos que exponer cómo va jugando Hegel con el concepto en la Fenomenología del espíritu y en la lógica. El juego del autorreconocimiento en la Fenomenología del espíritu, y el juego del concepto en la lógica; con eso ya entienden ustedes el modo hegeliano de llevar a cabo el lema anaxagórico: el todo está en todo, la unidad sintética de la idea absoluta. 